\section{Image analysis of optic nerve disease}

CF Burgoyne

(ONH) surface topography and retinal nerve fibre layer (RNFL) thickness within the peripapillary retina and within the macula. While a variety of technologies exist for measuring blood flow within the superficial layers of the optic nerve head, they do not yet have wide clinical application and are not discussed in this report.

\section{Definition of terms}

There are at present two principal tasks for these imaging systems. First, cross-sectional screening, in which an eye is imaged initially with the intention of detecting the presence of glaucomatous optic nerve damage. Second, longitudinal change detection, in which an eye that is already known to be at risk is imaged on multiple occasions over time with the intention of detecting change or progressive damage.

\section{Current instruments}

\section{Heidelberg retinal tomograph}

The Heidelberg retinal tomograph (HRT) is a confocal scanning laser ophthalmoscope (CSLO) that uses a $670 \mathrm{~nm}$ diode laser to obtain a series of two-dimensional optical section images of the $\mathrm{ONH}$ and peripapillary retina. A threedimensional topographic image of the $\mathrm{ONH}$ surface is then built from the series of 16-64 serial optical sections, when algorithms are used to find the surface at each of $256 \times 256$ (HRT I) or $384 \times 384$ (HRT II) pixels over a 10 or $15^{\circ}$ field of view. The HRT II automatically captures three consecutive $15^{\circ}$ images and from these generates a mean topographic image.

To process images, the optic disc margin (anterior scleral canal opening) is defined by a contour line placed around the inner margin of the peripapillary scleral ring. The standard reference plane for volumetric parameter calculation is then automatically determined as $50 \mu \mathrm{m}$ posterior to the mean peripapillary retinal height along the contour line between 350 and $356^{\circ}$; however, the reference plane
This lecture will concentrate on the existing methodologies for imaging the optic nerve head
Glaucoma Service

LSU Eye Center

New Orleans, LA, USA

Correspondence:

CF Burgoyne

Glaucoma Service LSU Eye

Center, 2020 Gravier Street

Suite B, New Orleans

LA 70112-2234, USA

Tel: + 15044121200

ext 1306

Fax: + 15044121315

Received: 4 September 2003

Accepted: 4 September 2003

Disclosure: I use a Heidelberg Retinal Tomograph in my clinic (purchased) and research laboratory (donated) to detect the onset and progression of glaucomatous optic nerve head damage. I am not a paid speaker for any of the instrument companies. I do have an intellectual (but no financial) interest in their development.

8


definition can be modified. Magnification is automatically adjusted by using the patients' keratometry readings and the power of the correction lens used to acquire the images.

For stereometric parameters, the mean coefficient of variation has been reported to be between 3 and $5 \%$ for both glaucoma and normal subjects. ${ }^{1}$ The mean standard deviation for individual pixels has been reported to be approximately $30 \mu \mathrm{m}$ in glaucoma eyes and $25 \mu \mathrm{m}$ in normal eyes. ${ }^{2,3}$ Individual pixel variability varies by region, being related to the steepness of the surface, and is highest at the edge of the optic disc cup and along vessels. The quality and variability of the images are associated with pupil size and density of nuclear and posterior subcapsular cataracts. ${ }^{4,5}$ In addition, HRT measurements are influenced by acute changes in intraocular pressure ${ }^{6,7}$ and even the cardiac cycle. ${ }^{8}$

Current limitations of the technology include the need to outline the anterior scleral canal opening and a reference plane and stereometric parameters that are dependent upon this delineation. While improvements in image acquisition have been built into the HRT II, the quality of the image still depends on the ability of the technician and requires training, experience, and dedication. Experienced technicians can acquire acceptable images in as many as $90 \%$ of eyes. Advanced cataract, corneal opacities, and nystagmus can prevent adequate imaging. Better automated quality control assessment at the time of image acquisition would warn the operator that new or additional images are necessary to ensure good data.

\section{Optical coherence tomography}

Optical coherence tomography (OCT) uses the principles of low-coherence interferometry to obtain high resolution, cross-sectional images of the human retina, peripapillary NFL, and ONH. In a manner analogous to B-scan ultrasonography, OCT utilises light echoes from the scanned tissue to discriminate retinal layers due to the differences in time delay of echoes from various components of the retina. The light source of the OCT is a short coherence length superluminescent diode in a nearinfrared wavelength $(840 \mathrm{~nm})$. Axial reflectance profiles (A-scans) are measured $v$ s depth. Tomographic images are constructed from a series of A-scans. The scan rate used is 128-512 lateral pixel retinal tomograms with a depth of $2-3 \mathrm{~mm}$ captured within $1 \mathrm{~s}$. The in vivo resolution of the Stratus OCT (Carl Zeiss Meditec, Inc., Dublin, CA, USA) is $8-10 \mu \mathrm{m}$ and the OCT 2000 is 10 $12 \mu \mathrm{m}$.

OCT is capable of scanning the peripapillary retina, $\mathrm{ONH}$ and macular region. The peripapillary scan is a continuous circular scan centred on the $\mathrm{ONH}$ with a default diameter of $3.4 \mathrm{~mm}$. Macular and $\mathrm{ONH}$ scans are composed of six radial scans in a spoke-like pattern centred on the $\mathrm{ONH}$ or the fovea at $30^{\circ}$ intervals. Interpolation is used to fill the gaps between the scans. For macular scans, the vitreoretinal interface and the retinal pigment epithelium are utilised to define the inner and outer retinal boundaries, respectively.

For ONH scans, the disc margin is defined as the end of the retinal pigment epithelium (RPE)/choriocapillaris layer. A straight line connects the edges of the RPE/ choriocapillaris, and a parallel line is constructed $150 \mu \mathrm{m}$ anteriorly. Structures below this line are defined as the disc cup and above this line as the neuroretinal rim. Additional OCT details can be found in the cited references. ${ }^{9-13}$

OCT RNFL measurements show good reproducibility, with intraclass coefficients of approximately $0.55^{14,15}$ and coefficients of variation of approximately $10 \%$. OCT RNFL thickness measurements increase after trabeculectomy-induced IOP reduction in glaucomatous eyes. OCT RNFL measurements are not affected by refraction changes within $\pm 5.0 \mathrm{D} .{ }^{16}$ In the presence of substantial media or lenticular opacities, scanning with OCT can be difficult. While it has been suggested that no pupillary dilation is required in patients with a pupil diameter $>2 \mathrm{~mm}$, there are no available studies reporting the percentage of patients (with or without media opacities) who require pupillary dilation for good OCT images, nor are there data as to the percentage of glaucoma patients in whom satisfactory results can be obtained.

\section{Scanning laser polarimetry}

Scanning laser polarimetry (SLP) estimates the thickness of the peripapillary retinal NFL based on the retardation of polarised light. Owing to their parallel architecture, the axonal microtubules of the NFL demonstrate form birefringence, which generates a net retardation of light that is proportional to the NFL's thickness (approximately $1^{\circ}$ of retardation per $7.4 \mu \mathrm{m}$ of thickness). ${ }^{17}$

To acquire an image, a polarised laser beam scans the peripapillary retina circumferentially around the scleral canal opening. The backscattered light (which doublepasses the RNFL) is captured and analysed. The amount of retardation is calculated per pixel and displayed in a retardation map of the scanned area. As the cornea, lens, and sclera also demonstrate form birefringence, their retardation needs to be compensated (neutralised) to isolate that due to RNFL retardation. ${ }^{18-26}$ Older versions of the instrument (NFL Analyzer, I and II, GDx and GDx Access) all employed a uniform, fixed compensation in which both axis and magnitude reflected median values 
of the general population. In the current version of the instrument (GDx-VCC), custom anterior segment birefringence compensation (ASBC) is employed, which utilises an initial scan of the patient's macula to perform patient-specific compensation. ${ }^{19}$

To acquire images with the GDx-VCC, two imaging trials per eye are run successively, the first to determine ASBC, the second to image the area of interest with adjusted ASBC. Image acquisition takes approximately $0.7 \mathrm{~s}$ per trial. Owing to the laser wavelength $(820 \mathrm{~nm})$, mild to moderate cataract does not degrade the images. ${ }^{27,28}$

Most literature on SLP pertains to the early versions of the instruments. A new normative database has been collected with the GDx-VCC. The variable ASBC has been demonstrated to generate accurate estimates of corneal polarisation axis and magnitude, both in healthy eyes and in eyes with maculopathy. ${ }^{19,26}$ Recent studies have demonstrated that custom ASBC narrows the band of normative data, ${ }^{20-22}$ improves the discriminating power for glaucoma detection, ${ }^{21,22}$ increases the correlation with structural assessments obtained with optical coherence tomography, ${ }^{24}$ and improves the correlation with red-free fundus photographs. ${ }^{25}$

Limitations include the following: Images cannot be obtained in eyes with nystagmus. Eyes with large peripapillary atrophy cannot be reliably imaged. Corneal refractive surgery has been demonstrated to variably affect measurements with fixed ASBC. ${ }^{29-31}$ The effectiveness of variable ASBC in eyes following corneal refractive surgery is currently unknown. Macular disease may affect the calculation of ASBC. ${ }^{26}$ Some eyes continue to show atypical retardation patterns. Histological validation in human eyes has not been done.

\section{Current performance-Cross-sectional screening}

In general, all of the instruments have achieved sensitivities and specificities within the 60-80th percentiles, with occasional studies suggesting that specificity can be pushed to greater than $90 \%$ in select populations. At present, this level of performance is unlikely to help the experienced examiner, though the performance of the instruments continues to improve.

\section{HRT}

A number of studies have evaluated the diagnostic performance of the HRT in groups of patients already diagnosed and attending glaucoma clinics. In general, three methods have been used: (i) linear discriminant functions; ${ }^{32,33}$ (ii) comparison of one (or more) stereometric parameters to normative database (the
Moorfields Regression Analysis); (iii) use of computerassisted classification such as neural networks. ${ }^{34,35}$ Each of these methods uses HRT parameters (global or sectorial) as inputs to discriminate between the normal and glaucomatous groups of eyes. In general, sensitivities of $62-87 \%$ and specificities from 80 to $96 \%$ have been reported. ${ }^{32,33,36-39}$ However, in most of these studies, this level of performance was achieved in a population similar to the one used to derive the original discriminant functions. Other studies have suggested that when the same strategy is applied to a new population, the diagnostic precision is not as good. ${ }^{40,41}$

HRT descriminating precision is influenced by disc size, with larger discs more precisely discriminated than smaller discs. ${ }^{37,41}$ HRT performance has been compared to stereo optic disc photography. Wollstein et $a l^{34}$ reported that for detection of early glaucoma, the Moorfields Regression Analysis had a higher sensitivity with equal specificity compared to the majority opinion of five clinician observers. However, Greaney et $a l^{42}$ and Zangwill et $a l^{39}$ found that clinicians qualitatively assessing stereo optic disc photographs performed as well as or better than the HRT.

\section{OCT}

OCT has been shown to discriminate between healthy and glaucomatous eyes with sensitivities and specificities ranging from 68 to $90 \% .{ }^{42-48}$ Fair to moderate agreement (Kappa $=0.51-0.73$ ) was found between expert observers for classifying OCT clinical printouts as healthy or glaucomatous with fair sensitivities (76-79\%) and specificities (68-81\%). ${ }^{43}$ Recent studies investigating OCT-measured macular thickness suggest differences between healthy and glaucomatous eyes. ${ }^{49,50}$ Some evidence suggests that OCT can detect RNFL thinning in ocular hypertensive eyes prior to the onset of achromatic visual field defects. ${ }^{47,51}$

\section{GDx}

The sensitivity and specificity of GDx measurements have only been reported for GDx models with fixed ASBC. Most of these published data relate to Caucasian populations, showing moderate discriminating power between healthy and glaucomatous eyes. ${ }^{52-64}$

\section{Current performance-Longitudinal change detection}

Only confocal scanning laser ophthalmoscopy has been seriously applied to the problem of longitudinal change detection, and very encouraging results are now available. Only those studies which report 'clinically specific' change detection strategies (or strategies that 
have demonstrated the ability to appropriately detect no change in unchanging normal eyes) are summarised below.

\section{HRT}

Three clinically specific change detection strategies have been assessed in longitudinally imaged human eyes. A superpixel strategy for $\mathrm{ONH}$ surface change detection (which has been incorporated into the existing HRT software) has been described by Chauhan et al ${ }^{65}$ and used to detect the onset of ONH surface change in 31 of 77 ocular hypertensive (OHT) patients prior to the onset of visual field changes. The technique performed with a 95\% specificity within 37 normal eyes, but required a total of three confirmatory tests to achieve that specificity. ${ }^{66}$

Kamal et al ${ }^{67,68}$ used a segmental strategy to detect change in 13 of 21 OHT visual field converter, 47 of 164 OHT visual field nonconverter and 0 of 21 normal eyes. Tan et al ${ }^{69}$ detected change in 17 of 20 OHT converters and one in 20 normal eyes by analysing $30^{\circ}$ sectors of rim area. However, they too required that change occur in two of three consecutive tests to achieve that specificity.

Additionally, using a similar CSLO (not the HRT) to image monkey eyes, the LSU Experimental Glaucoma Study reported higher sensitivity and specificity for optic disc change detection by CSLO (defined as a significant change in two of three selected CSLO parameters in two consecutive post-laser imaging sessions) as compared to three fellowship-trained glaucoma specialists using stereo photo images of the same eyes. ${ }^{70,71}$

\section{OCT}

There are no clinically specific change detection strategies published for OCT.

\section{$G D x$}

There are no clinically specific change detection strategies published for scanning laser polarimetry. Several studies have addressed monitoring progression in glaucoma or other optic neurodegenerative disease using the GDx. ${ }^{72,73}$

\section{Necessary studies}

These are by no means inclusive and much needs to be done by all three technologies:

(1) Evaluate screening performance in a population rather than an office-based study population.

(2) Develop contour line- and reference planeindependent screening and progression strategies.
(3) Reduce the number of confirmatory tests required for specific progression detection from the current number of three.

(4) Evaluate the rate of field conversion following change detection.

(5) Compare screening and change detection performance to glaucoma specialists using stereo photos.

(6) Determine the predictive values of each instrument for the onset of standard and BY automated perimetry defects in OHT patients.

(7) Determine if RNFL measurements correlate with histologically determined RNFL thickness in human eyes.

\section{Future directions}

\section{High-resolution OCT}

Drexler et $\mathrm{l}^{74}$ have introduced ultra-high resolution OCT for macular pathology with an axial image resolution of approximately $3 \mu \mathrm{m}$ as opposed to $10 \mu \mathrm{m}$ for standard OCT. Applications for the peripapillary and foveal retinal NFL thickness are actively under study.

\section{Neural network/machine learning classifiers and other postprocessing algorithms}

Neural network and machine classifiers utilise multiple parameters (both structural and functional) to improve the sensitivity and specificity of clinical decision making. Brigatti et $a l^{75}$ report the use of several neural network algorithms on a database of 185 eyes of patients with early glaucomatous visual field loss and 54 eyes of agematched normal control subjects. The information used included automated visual field and structural data (cup/disc ratio, rim area, cup volume, and nerve fibre layer height) from computerised image analysis. A backpropagation network with two intermediate layers assigned an estimated probability of being glaucomatous to each eye and correctly identified $88 \%$ of all eyes with $90 \%$ sensitivity and $84 \%$ specificity. Bowd et $a l^{35}$ used neural networks and linear discriminant functions that employed a variety of HRT data to improve glaucoma detection. Similar strategies are under active investigation for NFL thickness measurements.

\section{ONH susceptibility assessment}

The existing strategies for imaging the $\mathrm{ONH}$ surface are designed to either detect the presence of disease (crosssectional screening) or the progression of disease (longitudinal change detection). As we do not have a science of $\mathrm{ONH}$ susceptibility, we do not yet have imaging strategies for estimating whether a given optic 
nerve head will be susceptible to a given level of intraocular pressure or systemic blood pressure. It bears acknowledging that while we will discuss existing strategies for cross-sectional screening and longitudinal change detection, it is hoped that one day, we will possess not only these strategies for clinical monitoring, but also the equipment and knowledge necessary to assess ONH susceptibility, that is, decide at what level of IOP and blood pressure the connective tissues, glia, and axons of a particular $\mathrm{ONH}$ will remain stable.

\section{Acknowledgements}

This talk has been derived in part from the preliminary drafts of the First Global Consensus meeting of the Association of International Glaucoma Societies (AIGS) to which I am a contributing member. The final consensus meeting was scheduled to occur in San Diego on 13 and 14 November 2003. I acknowledge the authors of each section, Hans Lemij (GDx), Jeff Liebmann (OCT) and Marcelo Nicolela (HRT), their working groups and the AIGS, for the resource they have created.

\section{References}

1 Rohrschneider K, Kruse FE. Reproducibility of the optic nerve head topography with a new laser tomographic scanning device. Ophthalmology 1994; 101: 1044-1049.

2 Weinreb RN, Lusky M, Bartsch DU, Morsman D. Effect of repetitive imaging on topographic measurements of the optic nerve head. Arch Ophthalmol 1993; 111: 636-638.

3 Chauhan BC, LeBlanc RP, McCormick TA, Rogers JB. Testretest variability of topographic measurements with confocal scanning laser tomography in patients with glaucoma and control subjects. Am J Ophthalmol 1994; 118: 9-15.

4 Zangwill LM, Berry CC, Weinreb RN. Optic disc topographic measurements after pupil dilation. Ophthalmology 1999; 106: 1751-1755.

5 Zangwill L, Irak I, Berry CC, Garden V, de Souza Lima M, Weinreb RN. Effect of cataract and pupil size on image quality with confocal scanning laser ophthalmoscopy. Arch Ophthalmol 1997; 115: 983-990.

6 Azuara-Blanco A, Harris A, Cantor LB, Abreu MM, Weinland M. Effects of short term increase of intraocular pressure on optic disc cupping. Br J Ophthalmol 1998; 82: 880-883.

7 Bowd C, Weinreb RN, Lee B, Emdadi A, Zangwill LM. Optic disk topography after medical treatment to reduce intraocular pressure. Am J Ophthalmol 2000; 130: 280-286.

8 Chauhan BC, McCormick TA. Effect of the cardiac cycle on topographic measurements using confocal scanning laser tomography. Graefes Arch Clin Exp Ophthalmol 1995; 233: 568-572.

9 Hee MR, Izatt JA, Swanson EA, Huang D, Schuman JS, Lin $\mathrm{CP}$ et al. Optical coherence tomography of the human retina. Arch Ophthalmol 1995; 113(3): 325-332.
10 Huang D, Swanson EA, Lin CP, Schuman JS, Stinson WG, Chang W et al. Optical coherence tomography. Science 1991; 254(5035): 1178-1181.

11 Pedut-Kloizman R, Pakter HM, Schuman JS. Ophthalmic diagnosis using optical coherence tomography. Ophthalmol Clin North Am 1998; 11: 1178-1181.

12 Schuman JS, Hee MR, Puliafito CA, Wong C, PedutKloizman T, Lin CP et al. Quantification of nerve fiber layer thickness in normal and glaucomatous eyes using optical coherence tomography. Arch Ophthalmol 1995; 113(5): 586-596.

13 Schuman JS. Optical coherence tomography for imaging and quantification of nerve fiber layer thickness. In: Schuman JS (ed) Imaging in Glaucoma. Slack: Thorofare, NJ, 1996.

14 Carpineto P, Ciancaglini M, Zuppardi E, Falconio G, Doronzo E, Mastropasqua L. Reliability of nerve fiber layer thickness measurements using optical coherence tomography in normal and glaucomatous eyes. Ophthalmology 2003; 110: 190-195.

15 Schuman JS, Pedut-Kloizman T, Hertzmark E, Hee MR, Wilkins JR, Coker JG et al. Reproducibility of nerve fiber layer thickness measurements using optical coherence tomography. Ophthalmology 1996; 103(11): 1889-1898.

16 Bowd C, Zangwill LM, Blumenthal EZ, Vasile C, Boehm AG, Gokhale PA et al. Imaging of the optic disc and retinal nerve fiber layer: the effects of age, optic disc area, refractive error, and gender. J Opt Soc Am 2002; 19(1): 197-207.

17 Weinreb RN, Dreher AW, Coleman A, Quigley H, Shaw B, Reiter K. Histopathologic validation of Fourier-ellipsometry measurements of retinal nerve fiber layer thickness. Arch Ophthalmol 1990; 108: 557-560.

18 Greenfield DS, Knighton RW, Huang XR. Effect of corneal polarization axis on assessment of retinal nerve fiber analyzer thickness by scanning laser polarimetry. Am J Ophthalmol 2000; 129: 715-722.

19 Weinreb RN, Bowd C, Greenfield DS, Zangwill LM. Measurement of the magnitude and axis of corneal polarization with scanning laser polarimetry. Arch Ophthalmol 2002; 120: 901-906.

20 Greenfield DS, Knighton RW, Schiffman J, Feuer W. Normative retardation data corrected for corneal polarization axis using scanning laser polarimetry. Ophthalmic Surg Lasers 2003; 34: 165-171.

21 Greenfield DS, Knighton RW, Feuer W, Schiffman J, Zangwill L, Weinreb RN. Correction for corneal polarization axis improves the discriminating power of scanning laser polarimetry. Am J Ophthalmol 2002; 134: 27-33.

22 Weinreb RN, Bowd C, Zangwill LM. Glaucoma detection using scanning laser polarimetry with variable corneal polarization compensation. Arch Ophthalmol 2003; 120: 218-224.

23 Bowd C, Zangwill LM, Weinreb RN. Association between scanning laser polarimetry measurements using variable corneal polarization compensation and visual field sensitivity in glaucomatous eyes. Arch Ophthalmol 2003; 121: 961-966.

24 Bagga H, Greenfield DS, Feuer W, Knighton RW. Scanning laser polarimetry with variable corneal compensation and optical coherence tomography in normal and glaucomatous eyes. Am J Ophthalmol 2003; 135: 521-529.

25 Reus NJ, Colen TP, Lemij HG. Visualization of localized retinal nerve fiber layer defects with the GDx with 
individualized and fixed compensation of anterior segment birefringence. Ophthalmology 2003; 110: 1512-1516.

26 Bagga H, Greenfield DS, Knighton RW. Scanning laser polarimetry with variable corneal compensation: identification and correction for corneal birefringence in eyes with macular pathology. Invest Ophthalmol Vis Sci 2003; 44: 1969-1976.

27 Holló G, Süveges I, Nagymihály A, Vargha P. Scanning laser polarimetry of the retinal nerve fibre layer in primary open angle and capsular glaucoma. Br J Ophthalmol 1997; 81: 857-861.

28 Kremmer S, Pflug A, Heiligenhaus A, Fanihagh F, Steuhl KP. Laser scanning topography and polarimetry with implantation of intraocular lenses before and after cataract surgery. Klin Monatsbl Augenheilkd 1999; 214: 378-385.

29 Gurses-Ozden R, Pons ME, Barbieri C, Ishikawa H, Buxton $\mathrm{DF}$, Liebmann JM et al. Scanning laser polarimetry measurements after laser-assisted in situ keratomileusis. Am J Ophthalmol 2000; 129(4): 461-464.

30 Kook MS, Lee S, Tchah HW, Sung K, Park R, Kim K. Effect of laser in situ keratomileusis on retinal nerve fiber layer thickness measurements by scanning laser polarimetry. J Cataract Refract Surg 2002; 28(4): 670-675.

31 Choplin NT, Schallhorn SC. The effect of excimer laser photorefractive keratectomy for myopia on nerve fiber layer thickness measurements as determined by scanning laser polarimetry. Ophthalmology 1999; 106: 1019-1023.

32 Mikelberg FS, Parfitt CM, Swindale NV, Graham SL, Drance SM, Gosine R. Ability of the Heidelberg Retina Tomograph to detect early glaucomatous visual field loss. J Glaucoma 1995; 4: 242-247.

33 Bathija R, Zangwill L, Berry CC, Sample PA, Weinreb RN. Detection of early glaucomatous structural damage with confocal scanning laser tomography. J Glaucoma 1998; 7: 121-127.

34 Wollstein G, Garway-Heath DF, Fontana L, Hitchings RA. Identifying early glaucomatous changes. Comparison between expert clinical assessment of optic disc photographs and confocal scanning ophthalmoscopy. Ophthalmology 2000; 107: 2272-2277.

35 Bowd C, Chan K, Zangwill LM, Goldbaum MH, Lee TW, Sejnowski TJ et al. Comparing neural networks and linear discriminant functions for glaucoma detection using confocal scanning laser ophthalmoscopy of the optic disc. Invest Ophthalmol Vis Sci 2002; 43: 3444-3454.

36 Uchida H, Brigatti L, Caprioli J. Detection of structural damage from glaucoma with confocal laser image analysis. Invest Ophthalmol Vis Sci 1996; 37: 2393-2401.

37 Iester M, Mikelberg FS, Drance SM. The effect of optic disc size on diagnostic precision with the Heidelberg retina tomograph. Ophthalmology 1997; 104: 545-548.

38 Caprioli J, Park HJ, Ugurlu S, Hoffman D. Slope of the peripapillary nerve fiber layer surface in glaucoma. Invest Ophthalmol Vis Sci 1998; 39: 2321-2328.

39 Zangwill LM, Bowd C, Berry CC, Williams J, Blumenthal EZ, Sanchez-Galeana CA et al. Discriminating between normal and glaucomatous eyes using the Heidelberg retina tomograph, GDx nerve fiber analyzer, and optical coherence tomograph. Arch Ophthalmol 2001; 119: 985-993.

40 Miglior S, Casula M, Guareschi M, Marchetti I, Iester M, Orzalesi N. Clinical ability of Heidelberg retinal tomograph examination to detect glaucomatous visual field changes. Ophthalmology 2001; 108(9): 1621-1627.
41 Ford BA, Artes PH, McCormick TA, Nicolela MT, LeBlanc $\mathrm{RP}$, Chauhan BC. Comparison of data analysis tools for detection of glaucoma with the Heidelberg Retinal Tomograph. Ophthalmology 2003; 110: 1145-1150.

42 Greaney MJ, Hoffman DC, Garway-Heath DF, Nakla M, Coleman AL, Caprioli J. Comparison of optic nerve imaging methods to distinguish normal eyes from those with glaucoma. Invest Ophthalmol Vis Sci 2002; 43: 140-145.

43 Sanchez-Galeana C, Bowd C, Blumenthal EZ, Gokhale PA, Zangwill LM, Weinreb RN. Using optical imaging summary data to detect glaucoma. Ophthalmology 2001; 108: 1812-1818.

44 Bowd C, Zangwill LM, Berry CC, Blumenthal EZ, Vasile C, Sanchez-Galeana $\mathrm{C}$ et al. Detecting early glaucoma by assessment of retinal nerve fiber layer thickness and visual function. Invest Ophthalmol Vis Sci 2001; 42(9): 1993-2003.

45 Guedes V, Schuman JS, Hertzmark E, Wollstein G, Correnti A, Mancini R et al. Optical coherence tomography measurement of macular and nerve fiber layer thickness in normal and glaucomatous human eyes. Ophthalmology 2003; 110(1): 177-189.

46 Mistlberger A, Liebmann JM, Greenfield DS, Hoh ST, Ishikawa $\mathrm{H}$, Marmor $\mathrm{M}$ et al. Assessment of optic disc anatomy and nerve fiber layer thickness in ocular hypertensive subjects with normal short-wavelength automated perimetry. Ophthalmology 2002; 109(7): 1362-1366.

47 Hoh ST, Greenfield DS, Mistlberger A, Liebmann JM, Ishikawa H, Ritch R. Optical coherence tomography and scanning laser polarimetry in normal, ocular hypertensive, and glaucomatous eyes. Am J Ophthalmol 2000; 129: 129-135.

48 Soliman MA, Van Den Berg TJ, Ismaeil AA, De Jong LA, De Smet MD. Retinal nerve fiber layer analysis: relationship between optical coherence tomography and red-free photography. Am J Ophthalmol 2002; 133: 187-195.

49 Greenfield DS, Bagga H, Knighton RW. Macular thickness changes in glaucomatous optic neuropathy detected using optical coherence tomography. Arch Ophthalmol 2003; 121: $41-46$.

50 Lederer DE, Schuman JS, Hertzmark E, Heltzer J, Velazques LJ, Fujimoto JG et al. Analysis of macular volume in normal and glaucomatous eyes using optical coherence tomography. Am J Ophthalmol 2003; 135(6): 838-843.

51 Bowd C, Weinreb RN, Williams JM, Zangwill LM. The retinal nerve fiber layer thickness in ocular hypertensive, normal, and glaucomatous eyes with optical coherence tomography. Arch Ophthalmol 2000; 118: 22-26.

52 Weinreb RN, Shakiba S, Zangwill L. Scanning laser polarimetry to measure the nerve fiber layer of normal and glaucomatous eyes. Am J Ophthalmol 1995; 119: 627-636.

53 Choplin NT, Lundy DC, Dreher AW. Differentiating patients with glaucoma from glaucoma suspects and normal subjects by nerve fiber layer assessment with scanning laser polarimetry. Ophthalmology 1998; 105: 2068-2076.

54 Lauande-Pimentel R, Carvalho RA, Oliveira HC, Goncalves DC, Silva LM, Costa VP. Discrimination between normal and glaucomatous eyes with visual field and scanning laser polarimetry measurements [erratum appears in $\mathrm{Br} \mathrm{J}$ Ophthalmol 2002; 86 (6): 707]. Br J Ophthalmol 2001; 85(5): 586-591.

55 Funaki S, Shirakashi M, Yaoeda K, Abe H, Kunimatsu S, Suzuki $\mathrm{Y}$ et al. Specificity and sensitivity of glaucoma detection in the Japanese population using scanning laser polarimetry. Br J Ophthalmol 2002; 86(1): 70-74. 
$56 \mathrm{Xu}$ L, Chen PP, Chen YY, Takahashi Y, Wang L, Mills RP. Quantitative nerve fiber layer measurement using scanning laser polarimetry and modulation parameters in the detection of glaucoma. J Glaucoma 1998; 7: 270-277.

57 Tjon-Fo-Sang MJ, Lemij HG. Sensitivity and specificity of measurements with scanning laser polarimetry. Am J Ophthalmol 1997; 123: 62-69.

58 Trible J, Schultz RO, Robinson JC, Rothe TL. Accuracy of scanning laser polarimetry in the diagnosis of glaucoma. Arch Ophthalmol 1999; 117: 1298-1304.

59 Lee VWH, Mok KH. Retinal nerve fiber layer measurements by nerve fiber analyzer in normal subjects and patients with glaucoma. Ophthalmology 1999; 106: 1006-1008.

60 Weinreb RN, Zangwill L, Berry CC, Bathija R, Sample PA. Detection of glaucoma with scanning laser polarimetry. Arch Ophthalmol 1998; 116: 1583-1589.

61 Yamada N, Chen PP, Mills RP, Leen MM, Stamper RL, Lieberman MF et al. Glaucoma screening using the Scanning Laser Polarimeter. J Glaucoma 2000; 9: 254-261.

62 Sinai MJ, Essock EA, Fechtner RD, Srinivasan N. Diffuse and localized nerve fiber layer loss measured with scanning laser polarimetry: sensitivity and specificity of detecting glaucoma. J Glaucoma 2000; 9: 154-162.

63 Colen TP, Tjon-Fo-Sang MJH, Mulder PGH, Lemij HG. Reproducibility of measurements with the Nerve Fiber Analyzer (NFA/GDx). J Glaucoma 2000; 9: 363-370.

64 Colen TP, Lemij HG. Sensitivity and specificity of the GDx: clinical judgment of standard printouts $v$ s the number. J Glaucoma 2003; 12: 129-133.

65 Chauhan BC, Blanchard JW, Hamilton DC, LeBlanc RP. Technique for detecting serial topographic changes in the optic disc and peripapillary retina using scanning laser tomography. Invest Ophthalmol Vis Sci 2000; 41: 775-782.

66 Chauhan BC, McCormick TA, Nicolela MT, LeBlanc RP. Optic disc and visual field changes in a prospective longitudinal study of patients with glaucoma: comparison of scanning laser tomography with conventional perimetry and optic disc photography. Arch Ophthalmol 2001; 119: 1492-1499.
67 Kamal DS, Garway-Heath DF, Hitchings RA, Fitzke FW. Use of sequential Heidelberg retina tomograph images to identify changes at the optic disc in ocular hypertensive patients at risk of developing glaucoma. $\mathrm{Br}$ J Ophthalmol 2000; 84: 993-998.

68 Kamal DS, Viswanathan VC, Garway-Heath DF, Hitchings RA, Poinooswamy D, Bunce C. Detection of optic disc change with the Heidelberg retina tomograph before confirmed visual field change in ocular hypertensives converting to early glaucoma. Br J Ophthalmol 1999; 83: 290-294.

69 Tan JC, Hitchings RA. Approach for identifying glaucomatous optic nerve progression by scanning laser tomography. Invest Ophthalmol Vis Sci 2003; 44: 2621-2626.

70 Burgoyne CF, Mercante DE, Thompson HW. Change detection in regional and volumetric disc parameters using longitudinal confocal scanning laser tomography. Ophthalmology 2002; 109: 455-466.

71 Ervin JC, Lemij HG, Mills RP, Quigley HA, Thompson HW, Burgoyne CF. Clinician change detection viewing longitudinal stereophotographs compared to confocal scanning laser tomography in the LSU Experimental Glaucoma (LEG) Study. Ophthalmology 2002; 109: 467-481.

72 Hollo G, Vargha P. Scanning laser polarimetry vs frequencydoubling perimetry and conventional threshold perimetry: changes during a 12-month follow-up in preperimetric glaucoma. Acta Ophthalmol Scand 2001; 79: 403-407.

73 Colen TP, van Everdingen JAM, Lemij HG. Axonal loss in a patient with anterior ischemic optic neuropathy as measured with scanning laser polarimetry. Am J Ophthalmol 2000; 130: 847-850.

74 Drexler W, Sattmann H, Hermann B, Ko TH, Stur M, Unterhuber A et al. Enhanced visualization of macular pathology with the use of ultrahigh-resolution optical coherence tomography. Arch Ophthalmol 2003; 121: 695-706.

75 Brigatti L, Hoffman D, Caprioli J. Neural networks to identify glaucoma with structural and functional measurements. Am J Ophthalmol 1996; 121: 511-521. 